\title{
Energy, Nutrient and Economic Cross Indicators of Cropping Systems in Northern Italy
}

\author{
Nicola Castoldi, Luca Bechini* \\ Department of Plant Production, Università degli Studi di Milano \\ Via Celoria 2, 20133 Milano, Italy
}

Received: 31 August 2009. Accepted: 10 November 2009.

\begin{abstract}
Agro-ecological indicators are useful tools to provide synthetic representations of agricultural systems. Simple indicators can be combined to calculate cross indicators, for example efficiencies, calculated as a ratio between two simple indicators. In sustainability studies, efficiency is frequently calculated in energy terms (energy output / energy input); however, other "output" and "input" terms can be used. In this study, we evaluated how the ranking of systems changes when different metrics of agricultural production (economic gross margin vs. energy output) and resource use (nutrients inputs and surpluses, fossil energy inputs, economic costs) are used. The calculations were carried out for a study area in northern Italy (Sud Milano Agricultural Park), characterised by intensively cultivated arable cropping systems (cereals and forage crops).

Crop types were ranked differently when metrics changed. In general, maize (a highly productive crop) had good performances when evaluated using the output / input energy ratio, while rice was good when we used the ratios based on gross margin. When energy or monetary outputs were divided by $\mathrm{N}$ surplus, all crop types had very similar median values, suggesting a common energetic and economic efficiency of $\mathrm{N}$ use. Overall, different cross indicators may provide a different representation of the system studied. This means that it is not possible to provide a unique synthetic evaluation of sustainability, which instead depends on the indicator(s) chosen. We conclude that it is very important to clarify the objective of sustainability studies and to select accordingly the most adequate indicators.
\end{abstract}

Key-words: Efficiency, fossil energy, nutrient balance, sustainability assessment, variable cost.

\section{Introduction}

The evaluation of environmental impact of modern agriculture is an issue of increasing importance (Matson et al., 1997; Tilman et al., 2002). Different tools are available to describe and quantify the potential and actual impacts of agricultural systems: direct measurements, simulation models, and simple or composite indicators, each having different levels of applicability and different potential explanation of the system (Malkina-Pykh, 2002; Bockstaller and Girardin, 2003; Castoldi and Bechini, 2006).

Indicators are largely used, due to their simplicity and to the low amount of data necessary for the calculation. However, this simplicity may limit the analysis and the interpretation of the system. Simple indicators describe the perfor- mance or impact of a single aspect of agricultural systems (e.g. nutrient balance, gross income, pesticide exposure, etc.). Contrary to simulation models, simple indicators do not consider the relations among different aspects of agro-ecosystems, while composite indicators analyse these interactions using mathematical relations (e.g. a ratio) among simple indicators. Simple indicators are usually expressed per unit area or per unit yield, while composite indicators have more complex units, such as "economic unit per impact unit" or "energy unit per economic unit".

The choice of the units used for indicators is important: for example, van der Werf et al. (2007) demonstrated that the expression of the results per unit area or per unit product provides a different ranking among the systems 
analysed. Usually, composite indicators describe a ratio of flows, with the numerator representing the output flow, and the denominator the input flow. The use of the term "efficiency" is not always correct because frequently the ratio is calculated between two indicators with different units, and therefore the result is not dimensionless. For this reason, we use the term "cross indicator" to identify the ratio between two simple indicators.

An extensive environmental and economic analysis on agricultural systems in northern Italy has been recently conducted using 18 indicators (Bechini and Castoldi, 2009), separately describing economic performance, nutrient and energy management, potential impact of pesticide use (toxicity and exposure), and effect of crop management on soil quality. Only one of these indicators was a cross indicator, calculated as the ratio between output and input energy flows (two simple indicators), thus describing the dependency of food and feed production on non-renewable energy (Biermann et al., 1999). The output / input energy ratio uses at the numerator the calorific energy content of the above ground biomass, but does not take into account its quality (e.g. the potential use for human diet, the content of proteins or particular amino acids, the digestible percentage of biomass, the fibre or lignin content, etc.). The selling price of the products might, at least partially, surrogate the quality of biomass; therefore the energy output might be substituted with the gross margin, thus obtaining an economic/energetic cross indicator. For this reason, in this work we tested a set of indicators obtained as a ratio between two simple indicators: at the numerator we put either energy output or gross margin; at the denominator we put simple indicators describing the performance of cropping systems for some problematic issues in the Sud Milano Agricultural Park (PASM; Bechini and Castoldi, 2009).

\section{Materials and methods}

\subsection{Studied area and farms monitored}

The PASM $\left(45^{\circ} \mathrm{N}, 9^{\circ} \mathrm{E} ; 47,000\right.$ ha, of which 35,000 are agricultural) is a regional metropolitan agricultural Park embracing the city of Milan (northern Italy). The Park is located in a plain area (altitude from 80 to $160 \mathrm{~m}$ asl; aver- age slope of $0.3 \%$ ), with prevalence of loam, sandy-loam, and silt-loam soils. The climate is sub-humid; the average annual rainfall is about $950 \mathrm{~mm}$. Temperatures increase from January (average minimum: $-1.2{ }^{\circ} \mathrm{C}$ and maximum: 4.9 ${ }^{\circ} \mathrm{C}$ ) to July (average minimum: $17.7^{\circ} \mathrm{C}$ and maximum: $29.2{ }^{\circ} \mathrm{C}$ ). The annual reference evapotranspiration $\left(\mathrm{ET}_{0}\right)$ is on average $800 \mathrm{~mm}$ with a peak in July (daily average of $5 \mathrm{~mm} \mathrm{~d}^{-1}$ ); $\mathrm{ET}_{0}$ exceeds rainfall from May to September. The agricultural systems are intensive, with moderate to high yields. The most important crops are maize (Zea mays L.), rice (Oryza sativa L.), permanent meadows, winter barley (Hordeum spp.), Italian ryegrass (Lolium multiflorum Lam.), winter wheat (Triticum aestivum L.), triticale (Triticum $\times$ Secale), and soybean [Glycine $\max ($ L.) Merr.].

Seven farms were selected to collect detailed data about crop management (Bechini and Castoldi, 2009). These were two dairy farms, two swine farms, two rice farms, and a mixed farm. Livestock farms had different animal weight per unit area (animal density). These farms were visited periodically during the period October 2004 - October 2006, and, through face-to-face interviews with farmers, management data on 266 field $\times$ year combinations ("crops") were collected (125 maize, 51 rice, 62 permanent meadows, 12 winter wheat, 10 winter barley, 2 Italian ryegrass, 2 triticale, and 2 soybean).

The data were related to: tillage (date and type), sowing (date, dose, species, variety, and cost), fertiliser and manure application (date, dose, nutrient concentrations, and cost), pesticide application (date, dose, active ingredient concentrations, and cost), irrigation (date and type), harvest (date, yield, humidity, type of harvested product, and selling price). Livestock management was also monitored by collecting data about the number, average weight and type of animals on the farm and their feed rations.

\subsection{Simple and cross indicators}

A set of 15 indicators was selected from literature (Castoldi and Bechini, 2006; Castoldi et al., 2007) and calculated for each crop monitored; in addition, three indicators of soil management were calculated at the crop succession (i.e. field) level (Bechini and Castoldi, 2009). Out of the 18 indicators, we used only the following in this research: variable costs $(V C)$; gross margin 
Table 1. Cross indicators used to describe cropping systems management in the Sud Milano Agricultural Park (northern Italy). See the text (paragraph 2.2) for details on indicators calculation.

\begin{tabular}{|c|c|c|c|c|}
\hline & enominator & & $\longrightarrow$ & rator \\
\hline Indicator name & Acronym & Units & Energy output & Gross margin \\
\hline & & & $\operatorname{EnO}\left(\mathrm{GJ} \mathrm{ha}^{-1}\right)$ & $\mathrm{GM}\left(€ \mathrm{ha}^{-1}\right)$ \\
\hline Fossil energy inputs & EnIN & GJ ha-1 & $\mathrm{EnO} / \mathrm{EnIN}$ & GM/EnIN \\
\hline Variable costs & $\mathrm{VC}$ & $€ \mathrm{ha}^{-1}$ & $\mathrm{EnO} / \mathrm{VC}$ & GM/VC \\
\hline $\mathrm{N}$ input & NIN & $\mathrm{kg} \mathrm{N} \mathrm{ha}^{-1}$ & $\mathrm{EnO} / \mathrm{NIN}$ & GM/NIN \\
\hline$P$ input & PIN & $\mathrm{kg} \mathrm{P}_{2} \mathrm{O}_{5} \mathrm{ha}^{-1}$ & $\mathrm{EnO} / \mathrm{PIN}$ & GM/PIN \\
\hline $\mathrm{N}$ surplus & NS & $\mathrm{kg} \mathrm{N} \mathrm{ha}^{-1}$ & $\mathrm{EnO} / \mathrm{NS}$ & GM/NS \\
\hline P surplus & PS & $\mathrm{kg} \mathrm{P}_{2} \mathrm{O}_{5} \mathrm{ha}^{-1}$ & $\mathrm{EnO} / \mathrm{PS}$ & GM/PS \\
\hline
\end{tabular}

( $G M$, the difference between gross income and $V C) ; \mathrm{N}(N S)$ and $\mathrm{P}(P S)$ soil surface balances; the sum of direct and indirect energy inputs $(E n I N)$ for gasoline, lubricants, pesticides, fertilisers, seeds, and machinery (Biermann et al., 1999); energy output (EnO, calculated as the calorific energy content of the above ground biomass); and the output / input energy ratio $(E n O / E n I N)$.

Variable costs were the sum of the costs for pesticides, fertilisers, seeds, gasoline, and lubricants. Gross margin was calculated as the gross income (the yield of harvested product multiplied by its selling price) minus $V C$.

The soil surface balance (Parris, 1998) was calculated as the difference between the nutrients entering the soil and those leaving the soil with crop uptake. The nutrient inputs were calculated as the sum of the amounts of nutrients applied with chemical fertilisers and manures, nutrients returned to soil with residues originating from the previous crop, atmospheric deposition, biological fixation of leguminous crops; the output was the sum of nutrients removed from soil with crop residues, and with useful product exported from field. The amount of nutrients in the irrigation water was considered negligible. Ammonia volatilisation and denitrification were not considered because the information available was insufficient for their estimation; hence they are part of NS. Positive soil surface balances indicate nutrient accumulation in the soil or losses to the environment; negative balances indicate potential nutrient depletion from soil.

In the research presented here we calculated several cross indicators, using the ratio between $G M$ or $E n O$ (as numerator) and either EnIN, VC, N input (NIN), $\mathrm{P}$ input (PIN), NS or $P S$ as denominator (Tab. 1). We have chosen
$E n O$ and $G M$ as numerators ("output" term) in order to put the emphasis either on net primary productivity (amount of solar energy assimilated, regardless of the quality of biomass obtained) or on its economic value. The indicators used as denominators ("input" term) represent fluxes that enter or exit the agro-ecosystem, representing either an economic or energetic cost ( $V C$ and $E n I N)$, a nutrient input (NIN and $P I N)$, or a potential nutrient loss (NS and $P S)$; nonetheless, all these terms can be viewed as a support to crop cultivation, i.e. flows that are necessary to sustain agricultural production.

Cross indicators were calculated on 29 silage maize crops (MS), 96 grain maize (MG), 62 permanent meadows $(\mathrm{PM}), 51$ rice $(\mathrm{R}), 12$ winter wheat, and 10 barley (B). Cross indicators were calculated also on Italian ryegrass, soybean, and triticale (2 crops monitored for each species), but the results are not shown due to the small number of cases available.

\section{Results and discussion}

\subsection{Cross indicators}

The elevated energy investments in rice cultivation (corresponding to high $V C ; \mathrm{R}^{2}$ between $V C$ and $E n I N=0.78$ ) are economically profitable thanks to the high selling price, despite that the yield (and the corresponding $E n O$ ) is not particularly high compared to other crops. On the contrary, for maize the economic return is guaranteed by the large amount of biomass produced rather than by the price of the product. This explains the energy efficiencies depicted in Figure 1A, which were maximum for silage maize and minimum for rice: the low energy obtained from rice cultivation and the high energy inputs necessary for this crop yielded low val- 

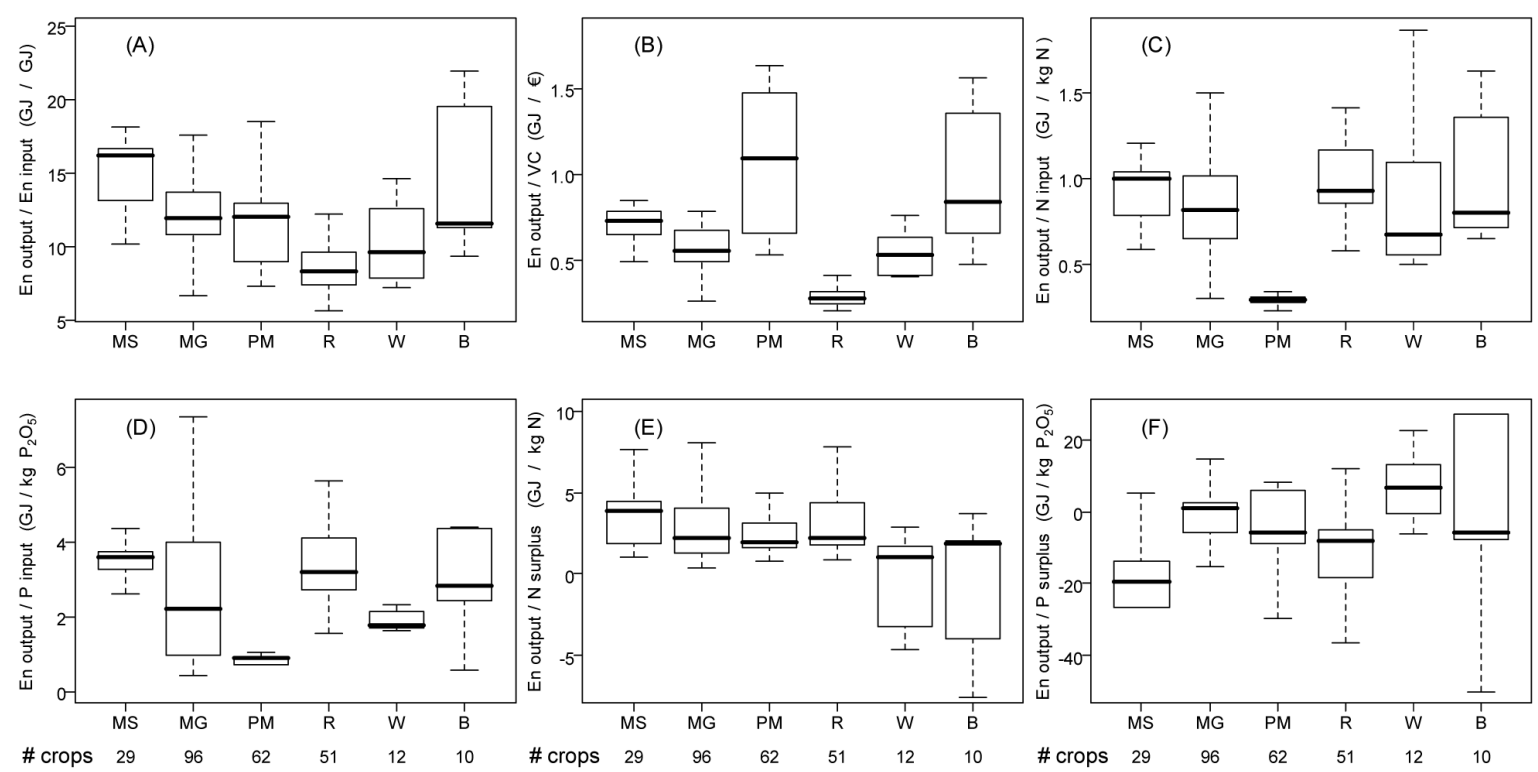

Figure 1. Boxplots representing the distributions of cross indicators, defined as the ratio among Energy Output ("En output" in the graphs) and either: (A) energy inputs ("En input" in the graphs), (B) variable costs (VC), (C) nitrogen inputs, (D) phosphorus inputs, (E) nitrogen surplus, or (F) phosphorus surplus calculated for 260 monitored crops over two years in the Sud Milano Agricultural Park (northern Italy). Crop types: MS: silage maize; MG: grain maize; PM: permanent meadows; R: rice; W: winter wheat; B: barley. The boxes indicate the $1^{\text {st }}$ and $3^{\text {rd }}$ quartiles of the distribution, the bold line is the median, and the bars are the maximum and minimum.

ues of EnO/EnIN (on average $8.6 \mathrm{GJ}^{\mathrm{GJ}}{ }^{-1}$; Fig. 1A); the opposite was true for maize (on average 15.0 and $12.6 \mathrm{GJ}^{\mathrm{GJ}}{ }^{-1}$ for MS and MG, respectively). For barley, the average value of EnO/EnIN was $14.7 \mathrm{GJ} \mathrm{GJ}^{-1}$ : barley easily exploits the residual soil fertility, and irrigation, pesticide application and post harvest operations are seldom necessary.

The energetic return of the invested money was studied by using $V C$ as denominator instead of EnIN (Fig. 1B). In this case, permanent meadows reached the best performance, with an average of $1.1 \mathrm{GJ} €^{-1}$; the median of rice was ranked in the last position, and maize was intermediate. As for the previous indicator, also in this case the high costs for rice production were not counteracted by a high quantity of biomass production. As previously noted for barley, the effectiveness of permanent meadows demonstrates the good performance of the extensive systems, when evaluated with these indicators $(E n O / E n I N$ and $E n O / V C)$.

The picture described by the energetic return of the nutrients applied (EnO/NIN, EnO/PIN; Fig. 1C and 1D) was rather different. Permanent meadows obtained the worst values, due to relatively large amounts of nutrients applied (through manure in particular), and to the fact that the yield of meadows was not particularly high in all the systems monitored (the dairy farm with the lower livestock density had remarkably lower yield for meadows compared to the other dairy farm). For the other crops (maize, rice, wheat and barley), assuming that the amount of $\mathrm{N}$ applied (NIN) was similar to that taken up in the crop aboveground biomass, the relative similarity of the median values of EnO/NIN (Fig. 1C) was probably due to the relatively narrow range of aboveground $\mathrm{N}$ concentrations $\left(1.05-1.55 \mathrm{~g} \mathrm{~N} \mathrm{~kg}^{-1}\right)$ and of specific calorific energy contents of biomass (16.8 19.0 $\mathrm{MJ} \mathrm{kg}^{-1}$ ).

The nutrient surpluses for maize were usually higher than for the other crop types (Bechini and Castoldi, 2009), but it is remarkable that the ratios among energy outputs and nutrient surpluses (Fig. 1E and 1F) were similar to those obtained for permanent meadows and rice (crops having lower nutrient balances); this was due to larger energy output for crops (like maize) that had higher nutrient surpluses. The energy return per unit of nutrient surplus there- 

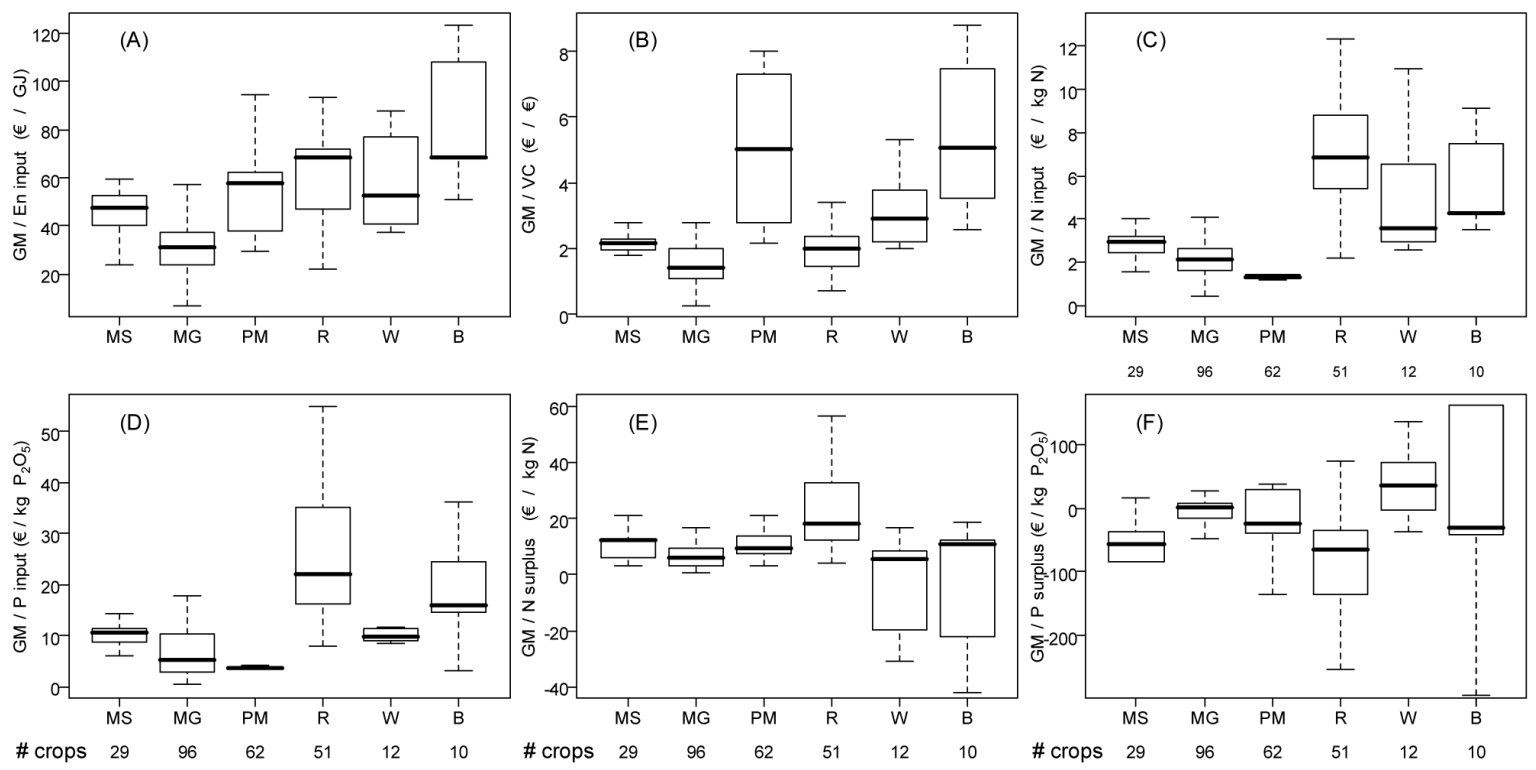

Figure 2. Boxplots representing the distributions of cross indicators, defined as the ratio among Gross Margin (GM) and either: (A) energy inputs ("En input" in the graphs), (B) variable costs (VC), (C) nitrogen inputs, (D) phosphorus inputs, (E) nitrogen surplus, or (F) phosphorus surplus calculated for 260 monitored crops over two years in the Sud Milano Agricultural Park (northern Italy). Crop types: MS: silage maize; MG: grain maize; PM: permanent meadows; R: rice; W: winter wheat; B: barley. The boxes indicate the $1^{\text {st }}$ and $3^{\text {rd }}$ quartiles of the distribution, the bold line is the median, and the bars are the maximum and minimum.

fore suggests that nutrient management for maize was not less effective than for other crops, because the environmental effect (nutrient surplus) was partially compensated by the high level of production. The foodstuff necessary for human and animal nutrition in a specific region can be obtained by cultivating a larger area in an extensive way or a smaller area intensively; in the latter case, the environmental pressure due to nutrient load is more concentrated. At the regional level the average environmental pressure is the same in the two cases, but the adoption of the intensive systems leaves more non-agricultural area to provide ecosystem services (e.g. recreation, conservation of biodiversity, regulation of water cycle; Tilman et al., 2002).

When gross margin was used to represent the output flow (as the numerator in the cross indicators; Fig. 2), crop types had a different ranking compared to when energy was used. Considering the economic return of invested energy (GM/EnIN; Fig. 2A), grain maize was on average the worst crop type $\left(34.3 € \mathrm{GJ}^{-1}\right)$, while barley performed very well $\left(82.9 € \mathrm{GJ}^{-1}\right)$. Even if with a statistical distribution richer in lower values, rice had a similar median compared to barley.
The economic efficiency (ratio between economic output and input, $G M / V C$; Fig. 2B) showed good results for barley and permanent meadows, due to their low cultivation costs. The other cereals scored relatively bad, due to high $V C$. Rice is cultivated on large areas in the PASM, despite its low economic efficiency; this suggests that farmers are more interested in the maximisation of the net return per unit area rather than per unit of money invested.

The gross margins obtained per nitrogen and per phosphorus input (GM/NIN, GM/PIN; Fig. 2C and 2D) were high for barley, wheat, and rice, due to low nutrient inputs. For these indicators, permanent meadows obtained very poor values due to low gross margin and high nutrient inputs.

Gross margin per $\mathrm{N}$ surplus (GM/NS; Fig. $2 \mathrm{E})$ was higher for rice and lower for the other crops; for grain maize (average $10.4 € \mathrm{~kg}^{-1} \mathrm{~N}$ ) the low $G M / N S$ was due to the elevated nitrogen surplus (176 kg N ha-1 on average; data not shown). Winter wheat and barley had in several cases negative values of $G M / N S$, due to negative $\mathrm{N}$ balances. The GM/PS ratio (Fig. $2 \mathrm{~F}$ ) was in many cases negative, in particular for silage 
maize and rice, because soils with a high concentration of extractable phosphorus (frequently found in the PASM: Castoldi et al., 2009) do not require $\mathrm{P}$ fertilisation; therefore in these cases $\mathrm{P}$ balances are negative.

Farmers cannot easily increase the numerator of the cross indicators presented in Figure 2 , because they cannot influence selling prices, and yields in the studied area are already elevated. Therefore, cross indicators related to nutrient use and economic output could be improved by optimising nutrient management. The optimisation of $\mathrm{N}$ and $\mathrm{P}$ management would reduce nutrient inputs and therefore surpluses. The improvement of nutrient management requires periodic preparation of nutrient management plans at the field level.

In addition, the large variability of cross indicators demonstrated that some of the systems monitored were managed better than others, indicating space for improvement in many situations.

\subsection{Rankings}

In order to compare the six crop types, the rank of each crop has been calculated separately for each cross indicator: the crop with the highest value for the indicator was assigned a rank equal to one, while the crop with the lowest value had a rank equal to 260 (260 being the number of crops monitored). Then we calculated the average of the ranks by crop type (Tab. 2). When ranks are averaged, it is obviously im- possible to find the limits 1 and 260 , because crops lying at the extremes of the distribution are averaged with other crops belonging to the same crop type. For example, even if barley would occupy the first ten positions, its mean of ranks would be $(1+2+3+\ldots+10) / 10=5.5$.

Silage maize in general obtained intermediate ranks (Tab. 2), with the exception of $E n O / E n I N$, that on average was better than for the other crops (position 63), due to the high biomass production and the corresponding $\mathrm{EnO}$; on the low-performance side for silage maize, EnO/PS and GM/PS had average ranks 199 and 186, respectively: this was due to the tendency to apply a high amount of manure in excess of crop needs. This is true for $\mathrm{N}$ (Bechini and Castoldi, 2006), but is even more important for P. For example, a maize crop that receives liquid dairy manures in excess of $\mathrm{N}$, will have a greater excess of $\mathrm{P}$ in relative terms, because this liquid dairy manure has a lower $\mathrm{N}: \mathrm{P}$ ratio (3.2) compared to maize plants (4.7; Grignani et al., 2003). Grain maize did not obtain good (i.e. low) average ranks for any cross indicator (they were all higher than 106), and obtained bad ranks for $G M / E n I N$ and $G M / V C$ (189 and 187, respectively). Permanent meadows obtained extreme ranks: good when economic costs were considered (for $\mathrm{EnO} / \mathrm{VC}$ and $G M / V C$ ), and bad for cross indicators related to nitrogen and phosphorus inputs (average ranks above 195). Rice obtained rather good results for

Table 2. Mean of ranks of cross indicators obtained for six crop types monitored in the Sud Milano Agricultural Park, northern Italy (the lower the rank, the better the performance of the crop type).

\begin{tabular}{|c|c|c|c|c|c|c|}
\hline & \multicolumn{6}{|c|}{ Crop type } \\
\hline & $\begin{array}{l}\text { Silage } \\
\text { maize }\end{array}$ & $\begin{array}{l}\text { Grain } \\
\text { maize }\end{array}$ & $\begin{array}{l}\text { Permanent } \\
\text { meadows }\end{array}$ & Rice & $\begin{array}{l}\text { Winter } \\
\text { wheat }\end{array}$ & Barley \\
\hline Number of crops monitored & 29 & 96 & 62 & 51 & 12 & 10 \\
\hline \multicolumn{7}{|l|}{ Cross indicator } \\
\hline $\mathrm{EnO} / \mathrm{EnIN}$ & 63 & 115 & 136 & 213 & 171 & 97 \\
\hline $\mathrm{EnO} / \mathrm{VC}$ & 102 & 142 & 61 & 239 & 158 & 68 \\
\hline $\mathrm{EnO} / \mathrm{NIN}$ & 86 & 116 & 235 & 77 & 129 & 94 \\
\hline $\mathrm{EnO} / \mathrm{PIN}$ & 76 & 131 & 217 & 81 & 138 & 98 \\
\hline $\mathrm{EnO} / \mathrm{NS}$ & 96 & 136 & 146 & 120 & 206 & 181 \\
\hline $\mathrm{EnO} / \mathrm{PS}$ & 199 & 113 & 133 & 160 & 74 & 124 \\
\hline GM/EnIN & 145 & 189 & 112 & 83 & 95 & 44 \\
\hline GM/VC & 148 & 187 & 54 & 156 & 94 & 40 \\
\hline GM/NIN & 113 & 152 & 222 & 37 & 71 & 46 \\
\hline GM/PIN & 109 & 162 & 195 & 44 & 99 & 66 \\
\hline GM/NS & 120 & 166 & 133 & 74 & 181 & 157 \\
\hline GM/PS & 186 & 106 & 133 & 179 & 72 & 135 \\
\hline Average rank & 120 & 143 & 148 & 122 & 124 & 96 \\
\hline
\end{tabular}


Ital. J. Agron. / Riv. Agron., 2010, 5:19-26

Table 3. Spearman correlation coefficients among pairs of cross indicators (for the acronyms, see Tab. 1).

\begin{tabular}{|c|c|c|c|c|c|c|c|c|c|c|c|c|}
\hline & $\mathrm{EnO} / \mathrm{EnIN}$ & $\mathrm{EnO} / \mathrm{VC}$ & $\mathrm{EnO} / \mathrm{NIN}$ & $\mathrm{EnO} / \mathrm{PIN}$ & $\mathrm{EnO} / \mathrm{NS}$ & $\mathrm{EnO} / \mathrm{PS}$ & $\mathrm{GM} / \mathrm{EnIN}$ & $\mathrm{GM} / \mathrm{VC}$ & GM/NIN & GM/PIN & GM/NS & $\mathrm{GM} / \mathrm{PS}$ \\
\hline $\mathrm{EnO} / \mathrm{EnIN}$ & 1.00 & 0.70 & 0.23 & 0.16 & 0.15 & 0.03 & 0.31 & 0.33 & 0.06 & 0.01 & -0.07 & 0.10 \\
\hline $\mathrm{EnO} / \mathrm{VC}$ & & 1.00 & -0.33 & -0.35 & -0.02 & 0.17 & 0.30 & 0.71 & -0.35 & -0.36 & -0.11 & 0.23 \\
\hline $\mathrm{EnO} / \mathrm{NIN}$ & & & 1.00 & 0.80 & 0.43 & -0.19 & 0.17 & -0.29 & 0.79 & 0.69 & 0.31 & -0.19 \\
\hline $\mathrm{EnO} / \mathrm{PIN}$ & & & & 1.00 & 0.43 & -0.34 & 0.14 & -0.27 & 0.69 & 0.86 & 0.33 & -0.36 \\
\hline $\mathrm{EnO} / \mathrm{NS}$ & & & & & 1.00 & -0.17 & 0.09 & 0.00 & 0.25 & 0.37 & 0.86 & -0.12 \\
\hline $\mathrm{EnO} / \mathrm{PS}$ & & & & & & 1.00 & 0.05 & 0.16 & -0.08 & -0.26 & -0.16 & 0.97 \\
\hline GM/EnIN & & & & & & & 1.00 & 0.78 & 0.55 & 0.49 & 0.38 & -0.04 \\
\hline GM/VC & & & & & & & & 1.00 & 0.04 & 0.03 & 0.22 & 0.11 \\
\hline GM/NIN & & & & & & & & & 1.00 & 0.84 & 0.41 & -0.15 \\
\hline GM/PIN & & & & & & & & & & 1.00 & 0.49 & -0.32 \\
\hline GM/NS & & & & & & & & & & & 1.00 & -0.17 \\
\hline GM/PS & & & & & & & & & & & & 1.00 \\
\hline
\end{tabular}

most cross indicators related to $G M$; the two indicators that on average did not perform well for rice were EnO/EnIN (213) and EnO/VC (239), due to the low energy output (on average 194 GJ ha ${ }^{-1}$ ). Winter wheat obtained good average ranks for indicators where the output flow was $G M$, with the exception of $G M / N S$ (181), while for the cross indicators related to $E n O$ the average ranks were in general higher, with a maximum value for EnO/NS (206). Barley performed well, and usually the average ranks were low, with the exception of EnO/NS; for this crop the average of ranks for all cross indicators was equal to 96 (Tab. 2), the lowest among the crop types compared here. The single crop that obtained the lowest average rank (42.4) was a grain maize cultivated in the intensive swine farm, that obtained ranks lower than 50 for eight indicators and higher values for $G M / P S$ (59), EnO/PS (63), GM/PIN (143) and EnO/PIN (158).

The mean of ranks demonstrated that there was not a "best" crop type that on average performed better than the others for all the cross indicators considered: none of the 260 crops monitored had a rank lower than 100 for all the 12 cross indicators. This was also partly demonstrated by the Spearman correlation coefficient calculated between pairs of indicators (Tab. 3); this coefficient was usually low when calculated between cross indicators with different input flows, and high for many cross indicators with the same input flow (e.g. between EnO/PS and $G M / P S$, and between EnO/VC and $G M / V C$ ).

Cross indicators discriminated the performance of crop types and provided in some cases a different picture compared to that of simple indicators (Bechini and Castoldi, 2009). For example, by definition, excessive nutrient surpluses (not rated well when considered as single indicators) were a concern for maize and not for rice (Bechini and Castoldi, 2009); however, when surpluses were related to economic or energy production, the differences were much less pronounced: the cross indicators GM/NS (and $E n O / N S$ ) state that $\mathrm{N}$ management in maize (frequently characterised by excessive $\mathrm{N}$ application and high $\mathrm{N}$ surplus), when analysed in relative terms, was not so different from $\mathrm{N}$ management of the other crop types. The performances of barley were good when analysed both by simple indicators (Bechini and Castoldi, 2009) and cross indicators. The performance of permanent meadows was rather good if several simple indicators (soil management, energy inputs, pesticide use, nutrient surplus) were used (Bechini and Castoldi, 2009); the picture changed, however, with cross indicators, due to the relatively low (if compared to cereals) dry matter production.

Comparisons like the one presented here are not frequent. Van der Werf et al. (2007) have compared three management scenarios for pig farming, using five evaluation methods that differed for several aspects, including the mode of expression of the results (for the farm as a whole, per unit area or per unit product). They found out that the relative ranking of the three scenarios varied considerably depending on the method and, specifically, on the mode of expression of results. Their conclusion was that results should be expressed both per unit area and per unit product.

We have seen that efficiencies may vary substantially according to the output (numerator) and input (denominator) term chosen for the analysis. What can be then recommended to carry out sustainability evaluations? It should be 
reminded that simple indicators would either promote intensive systems with high biomass production (if output indicators are chosen) or low-input / low-emission systems (if pressure indicators are used). Therefore, we suggest that cross indicators, which provide a useful synthesis of two (sometimes competing) issues, should be included and evaluated together with simple indicators, to obtain a broad and comprehensive sustainability assessment. Another option is to calculate indexes that integrate several indicators into a unique value (e.g. Meul et al., 2008).

\section{Conclusions}

In order to describe the relations among outputs and inputs of arable cropping systems in northern Italy, a set of cross indicators was calculated using simple agro-ecological and economic indicators. These indicators provided a different picture of cropping systems compared to the application of simple indicators. Moreover, we evaluated the changes in ranking of arable crops sustainability when different metrics of productivity and costs (either environmental or economic) were used. Crop types were ranked differently when metrics changed, with good scores for maize if energy productivity was considered, and for rice when economic productivity was adopted.

When decision makers have to define the agricultural and environmental policies, they need specific tools to describe the sustainability of different agricultural management practices. These assessments have to be based both on the evaluation of a single issue (usually through simple indicators, e.g. energy consumption, nutrient losses, pesticide impact, etc.) and on the efficiency of the agricultural processes, described by composite indicators, such as the cross indicators analysed here. This research showed that the judgement on crop management obtained by simple indicators is not the same compared to that obtained with cross indicators.

Therefore, when planning a sustainability assessment, it is important to clearly define the objective of the research, together with all the stakeholders involved. Then the indicators (simple or cross) can be tailored to the specific objectives of the assessment.

\section{References}

Bechini L., Castoldi N. 2006. Calculating the soil surface nitrogen balance at regional scale: example application and critical evaluation of tools and data. Ital. J. Agron. / Riv. Agron. 1:665-676.

Bechini L., Castoldi N. 2009. On-farm monitoring of economic and environmental sustainability: results of a two-year study at the field scale in northern Italy. Ecol. Indicat., 9:1096-1113.

Biermann S., Rathke G.-W., Hülsbergen K.-J., Diepenbrock W. 1999. Energy recovery by crops in dependence on the input of mineral fertiliser. Research Report, Agrarökologisches Institut und Institut für Ackerund Pflanzenbau der Martin-Luther-Universität HalleWittenberg. EFMA Publication. (Online). Available at http://www.efma.org/EPUB/easnet.dll/GetDoc?APPL=1\&DAT_IM=000EA0\&DWNLD=endbericht.pdf; verified November 28, 2008. 49 pp.

Bockstaller C., Girardin P. 2003. How to validate environmental indicators. Agric. Syst., 76:639-653.

Castoldi N., Bechini L. 2006. Agro-ecological indicators of field-farming systems sustainability. I. Energy, landscape and soil management. Riv. Ital. Agrometeorol./ Ital. J. Agrometeorol., 1:19-31.

Castoldi N., Bechini L., Stein A. 2009. Evaluation of the spatial uncertainty of agro-ecological assessments at the regional scale: The phosphorus indicator in northern Italy. Ecol. Indicat., 9:902-912.

Castoldi N., Finizio A., Bechini L. 2007. Agro-ecological indicators of field-farming systems sustainability. II. Nutrients and pesticides. Riv. Ital. Agromet. / Ital. J. Agromet., 12:6-23.

Grignani C., Bassanino M., Sacco D., Zavattaro L. 2003. Il bilancio degli elementi nutritivi per la redazione del piano di concimazione. Riv. Agron. 37:155-172.

Malkina-Pykh I.G. 2002. Integrated assessment models and response function models: pros and cons for sustainable development indices design. Ecol. Indicat., 2:93-108.

Matson P.A., Parton W.J., Power A.G., Swift M.J. 1997. Agricultural Intensification and Ecosystem Properties. Science, 277:504-509.

Meul M., Van Passel S., Nevens F., Dessein J., Rogge E., Mulier A., Van Hauwermeiren A. 2008. MOTIFS: a monitoring tool for integrated farm sustainability. Agron. Sustain. Dev., 28:321-332.

Parris K. 1998. Agricultural nutrient balances as agri-environmental indicators: an OECD perspective. Envir. Poll., 102, S1:219-225.

Tilman D., Cassman K.G., Matson P.A., Naylor R., Polasky S. 2002. Agricultural sustainability and intensive production practices. Nature, 418:671-677.

Van der Werf H.M.G., Tzilivakis J., Lewis K., BassetMens C. 2007. Environmental impacts of farm scenarios according to five assessment methods. Agric. Ecosyst. Environ., 118:327-338. 